\title{
Distribuição de água no solo aplicado por gotejamento enterrado e superficial ${ }^{1}$
}

\author{
Allan C. Barros ${ }^{2}$, Marcos V. Folegatti ${ }^{2}$, Claudinei F. Souza ${ }^{3}$ \& Bruno L. Santoro ${ }^{4}$
}

\begin{abstract}
RESUMO
Devido à falta de estudos sobre o movimento da água quando aplicada abaixo da superfície, realizou-se este trabalho com o objetivo de avaliar a distribuição de água aplicada pelo sistema de gotejamento enterrado e convencional. O experimento de campo foi conduzido na área experimental do Departamento de Engenharia Rural da ESALQ/USP - Piracicaba, SP. Para o estudo, trincheiras foram abertas e instaladas sondas de TDR, dispostas a 0,05; 0,15;0,25; 0,35 e $0,45 \mathrm{~m}$ profundidade, e a 0,$05 ; 0,15 ; 0,25 ; 0,35 \mathrm{~m}$ comprimento, totalizando 17 sondas por trincheira. Os tratamentos foram baseados na profundidade de aplicação $(0,0$ e 0,10 m) e vazão aplicada (2 e 4 L h-1): ENT2; ENT4; SUP2 e SUP4. A cada hora era aplicado $1 \mathrm{~L}$ de água (total de $10 \mathrm{~L}$ ), seguida de leituras com o TDR. Medições do disco úmido e saturado foram feitas com régua milimetrada; além disso, estabeleceu-se um volume controle onde foi avaliada a uniformidade de aplicação; assim, foi possível verificar, em relação aos sistemas superficiais, que os sistemas enterrados apresentaram menor área superficial molhada e atingiram maior largura e profundidade; já as maiores concentrações foram obtidas próximas ao ponto de emissão.
\end{abstract}

Palavra-chave: bulbo úmido, relação água-solo, TDR

\section{Soil water distribution for subsurface and surface drip irrigation}

\begin{abstract}
Studies of sub-surface water movement is an interesting topic in irrigation but, in spite of the its importance, there is little literature. One of the purposes of this study was to contribute to this subject and evaluate the distribution of water applied by both subsurface drip irrigation (SDI) and conventional irrigation. Experiments were conducted at the Department of Rural Engineering (ESALQ/USP), located at Piracicaba, SP. Trenches were opened and 17 three-rod TDR probes were installed, placed at $0.05,0.15,0.25,0.35$ and $0.45 \mathrm{~m}$ depths, and to $0.05,0.15,0.25,0.35 \mathrm{~m}$ intervals. This procedure was repeated using a dripper buried at 0 and $0.10 \mathrm{~m}$ for each discharge rate of 2 and $4 \mathrm{~L} \mathrm{~h}^{-1}$ tested. Wetted soil volume was observed with $1 \mathrm{~L}$ of water applications at intervals (total $10 \mathrm{~L}$ ). The saturated disc around the dripper and the advance of the wetting front on the soil surface were measured with a ruler. Also, a central control volume was established inside the wetted soil volume where the uniformity of application was evaluated. The results suggest that SDI presented smaller wetted soil surface area and it reached larger distance and depth with greater storage of solution adjacent to the dripper.
\end{abstract}

Key word: wetted soil volume, water-soil relationship, TDR

\footnotetext{
1 Trabalho extraído da dissertação de mestrado em irrigação e drenagem, do primeiro autor

2 ESALQ/USP. Av. Pádua Dias 11, Piracicaba, SP. CEP 13418-900. Fone: (19) 3447-8554. E-mail: allan.cunha.barros@gmail.com; mvfolega@esalq.usp.br

${ }_{3}^{3}$ CCA/UFSCar. Rod. Anhanguera, km 174, SP-330, Araras-SP. CEP 13600-970. Fone: (19) 35432-616. E-mail: cfsouza@cca.ufscar.br

${ }^{4}$ UNITAU. Rua Exped. Ernesto Pereira 99, Centro, Taubaté, SP. CEP 12020-330. Fone: (12) 3625-4294 . E-mail: blsantoro@hotmail.com
} 


\section{INTRODUÇÃO}

Quando bem manejada, a irrigação por gotejamento permite maior eficiência de aplicação de água e nutrientes (fertirrigação); este sistema pode ser utilizado de duas formas: na superfície ou enterrado, também chamado sistema de irrigação subsuperficial.

Devido ao elevado custo das áreas produtivas de cana em São Paulo, a adoção de técnicas, como o gotejamento enterrado, é alternativa técnica para aumentar os índices de produtividade. Este sistema também é utilizado em outras culturas, como tomate (Marouelli \& Silva, 2002), melão (Monteiro, 2007), mamão (Coelho et al., 2005a), alface (Gomes \& Sousa, 2002), café (Faria et al., 2004) e citros (Coelho et al., 2006).

O sistema de gotejamento enterrado apresenta, como vantagens em relação ao superficial, a flexibilidade do uso de maquinário agrícola, maior dificuldade na germinação de sementes de ervas daninhas, uma vez que o solo se mantém seco na superfície, e menor redução da produção quando do uso de água salina (Oron et al., 1991); além disso, o sistema enterrado apresenta maior disponibilidade de nutrientes, visto que o ponto de emissão se encontra mais próximo da raiz, fato importante no manejo da fertirrigação; por outro lado, informações sobre o movimento simultâneo da água e dos sólidos dissolvidos, são escassas (Clothier \& Sauer, 1988).

O bulbo ou volume úmido do solo, é a distribuição de água no volume molhado por gotejamento; é, também, uma ferramenta indispensável na determinação de quanto e quando irrigar. O bulbo pode ser medido diretamente em campo, através da abertura de trincheiras ou de medidas indiretas, como tabelas ou modelos. Devido a especificidade dos solos, tabelas ajustadas para todos nem sempre são adequadas para os solos do Brasil, tornando imprescindíveis estudos que os caracterizem.

Altas tecnologias, como o sistema por gotejamento enterrado, só se tornam viáveis se forem utilizadas técnicas adequadas de manejo de irrigação que visem à racionalização do uso da água e ao aumento da produtividade (Coelho et al., 1999), tornando-se necessário o conhecimento do movimento de água quando aplicado em profundidade; daí se propôs, este trabalho, avaliar a distribuição de água no solo aplicada pelo sistema de gotejamento enterrado, em comparação com o convencional.

\section{MATERIAL E MÉTODOS}

O experimento foi conduzido de julho a agosto de 2007, no campus experimental da Fazenda Areão, Escola Superior de Agricultura 'Luiz de Queiroz' - ESALQ/USP, no município de Piracicaba, SP (22 $42^{\prime}$ S; $47^{\circ} 38^{\prime} \mathrm{W}$ altitude de $435 \mathrm{~m}$ ). O solo utilizado é classificado como Nitossolo vermelho, segundo a classificação brasileira de solos (EMBRAPA, 1999); a densidade média do solo é de $1210 \mathrm{~kg} \mathrm{~m}^{-3}$ e os valores de capacidade de campo e ponto de murcha permanente são: 0,45 e $0,25 \mathrm{~m}^{3} \mathrm{~m}^{-3}$; sua classe textural pode ser vista na Tabela 1.
Tabela 1. Análise granulométrica do solo para as profundidades de $0-0,2$ e $0,2-0,4 \mathrm{~m}$

\begin{tabular}{ccccc}
\hline Profundidade $(\mathbf{m})$ & Areia (\%) & Silte (\%) & Argila (\%) & Classe Textural \\
$0-0,2$ & 28,53 & 26,41 & 45,06 & Argilosa \\
$0,2-0,4$ & 28,92 & 24,57 & 46,51 & Argilosa \\
\hline
\end{tabular}

Os tratamentos se basearam na profundidade de emissão $(0,0$ e $0,1 \mathrm{~m})$ e na vazão (2 e $\left.4 \mathrm{~L} \mathrm{~h}^{-1}\right)$, totalizando 4 tratamentos, com três repetições cada um.

Aplicou-se $1 \mathrm{~L}$ de água a cada hora, no total de 10 aplicações; já o monitoramento da distribuição da solução foi realizado antes e após a aplicação; além disso, foram contabilizados o tamanho da poça saturada formada no momento da infiltração e o avanço da frente de umedecimento, por meio de uma régua milimetrada.

As leituras de umidade foram monitoradas através de Reflectômetro TDR100 e sondas. As sondas utilizadas no experimento foram construídas em parceria com o Laboratório de Mecânica dos Solos da Universidade de Taubaté, seguindo-se o procedimento descrito por Souza et al. (2006) e instaladas em seis trincheiras de 0,6 x 0,6 x 0,75 m (comprimento, largura e profundidade). Dezessete sondas por trincheira foram instaladas em malha (Figura 1 ) a 0,$05 ; 0,15$; 0,$25 ; 0,35$ e $0,45 \mathrm{~m}$ de profundidade e a 0,$05 ; 0,15 ; 0,25$; 0,35 m de distância do ponto do emissor, em que cada uma representava uma área de $0,01 \mathrm{~m}^{2}$, promovendo “medidas pontuais”. A distribuição das sondas foi baseada em Nogueira et al. (2000).

Superfície do solo

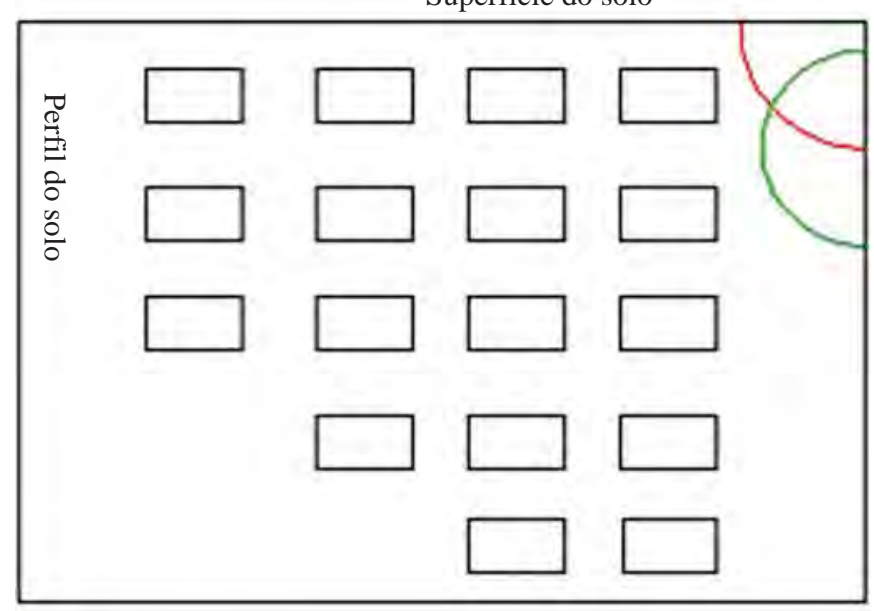

— Bulbo formado pelo emissor superficial

- Bulbo formado pelo emissor enterrado $(0,10 \mathrm{~m})$

Sondas de TDR

Figura 1. Disposição das sondas no perfil do solo para monitoramento da formação do bulbo no sistema de gotejamento enterrado e superficial

Devido à diferença nas propriedades físicas do solo e, conseqüentemente, na distribuição de água no solo, ocasionadas pela movimentação do solo, as leituras só foram realizadas após período de reestruturação de aproximadamente 
dois meses. A calibração do solo para a umidade teve como base a equação obtida por Tommaselli \& Bacchi (2001).

De posse dos dados foram feitos gráficos em três dimensões, confeccionados no programa Surfer Mapping System, o que apresentou o perfil de distribuição da umidade do solo, durante todo o ensaio, proporcionando informações básicas sobre a dinâmica da água no solo.

Por outro lado, adotou-se um volume central dentro do bulbo molhado, ou seja, 0,20 x 0,20 x 0,20 m respectivamente, comprimento, largura e profundidade, tomando-se como referência o gotejador superficial para se efetuar uma análise de uniformidade comparativa, com o propósito de entender as diferenças entre os valores de umidade do volume de controle; desta forma, os coeficientes de uniformidade de Christiansen (1941) foram calculados para as umidades estimadas após cada aplicação da solução, por meio da equação a seguir, seguindo-se a metodologia adaptada por Ould Mohamed El-Hafedh et al. (2001) e Wu \& Gitlin (1983).

$$
\mathrm{UC}=\left(1-\frac{\sum_{\mathrm{i}=1}^{\mathrm{n}} \mathrm{Xi}-\mathrm{Xm}}{\mathrm{nXm}}\right)
$$

em que:

UC - Coeficiente de Uniformidade de Christiansen, em \% (Christiansen, 1941)

$\mathrm{Xi}$ - Umidade volumétrica estimada, $\mathrm{m}^{3} \mathrm{~m}^{-3}$, ou concentração de nutriente estimado, dS m-1

$\mathrm{Xm}$ - Umidade volumétrica média, $\mathrm{m}^{3} \mathrm{~m}^{-3}$, ou concentração média do nutriente, $\mathrm{dS} \mathrm{m}^{-1}$

$\mathrm{n}$ - número de pontos estimados

Fez-se a aplicação de água por sistema de irrigação por gotejamento com emissores autocompensantes. Para evitar a movimentação do solo no ato da instalação das suas linhas, utilizaram-se distribuidores de descarga, de duas saídas, nos emissores dispostos na superfície; uma saída foi bloqueada e na outra instalada um microtubo (diâmetro interno = 3,0 mm); com o auxílio de trado fez-se a instalação na profundidade desejada.

\section{RESULTADOS E DISCUSSÃO}

Para facilitar a discussão dos resultados, os tratamentos foram codificados em: ENT2, Sistema de gotejamento enterrado de vazão $2 \mathrm{~L} \mathrm{~h}^{-1}$; ENT4, Sistema de gotejamento enterrado de vazão $4 \mathrm{~L} \mathrm{~h}^{-1}$; SUP2, Sistema de gotejamento superficial de vazão $2 \mathrm{~L} \mathrm{~h}^{-1}$ e SUP4 e Sistema de gotejamento superficial de vazão $4 \mathrm{~L} \mathrm{~h}^{-1}$.

Na Figura 2 se apresentam os dados referentes à área superficial molhada e ao disco saturado, para as vazões de 2 e $4 \mathrm{~L} \mathrm{~h}^{-1}$ nos sistemas de gotejamento superficial e enterrado. Não houve estabilização na formação da área molhada para a vazão de $2 \mathrm{~L} \mathrm{~h}^{-1}$, mostrando-se crescente, o que também ocorreu para a vazão de $4 \mathrm{~L} \mathrm{~h}^{-1}$.

Conclui-se, portanto, que a alta freqüência promoveu armazenamento superficial da solução no solo, mesmo após inúmeras aplicações, contrariando observações realizadas por

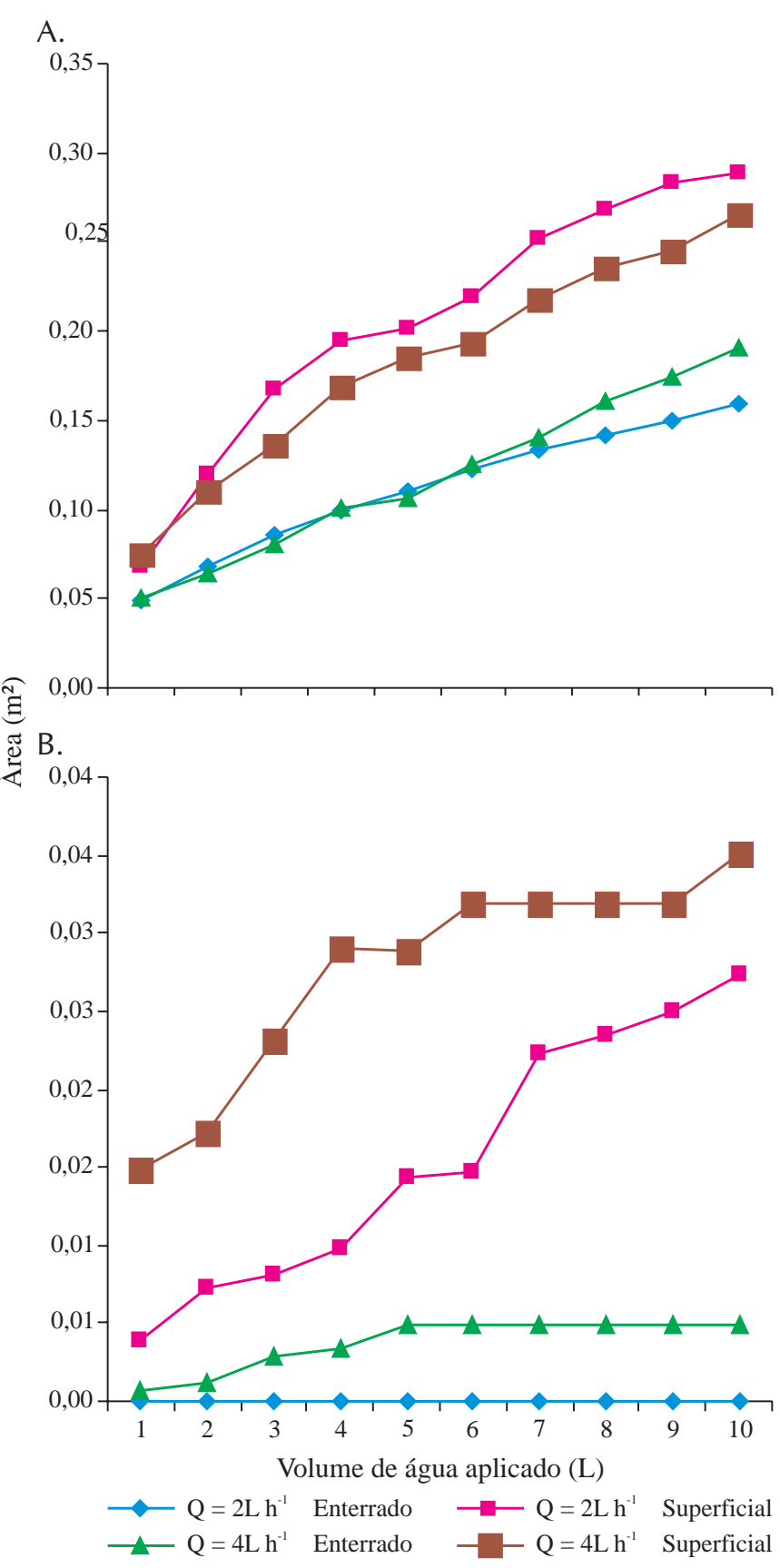

Figura 2. Área superficial molhada (A) e disco saturado (B) para as vazões de 2 e $4 \mathrm{~L} \mathrm{~h}^{-1}$, nos sistemas de gotejamento superficial e enterrado

Souza et al. (2007) ao relatarem que, para um solo arenoso, aplicações contínuas de água via gotejamento promovem o fenômeno de lixiviação, observando-se estabilização da área superficial molhada após 6 aplicações de 1 L, em intervalos de 1 h. Em comparação com os outros tratamentos, o sistema SUP4, demonstrou maior superfície molhada, só sendo menor que o SUP2, apesar da menor vazão; uma das explicações para o fato é que a aplicação da solução ao solo para o SUP2 foi iniciada no dia 02/07/2007 às $10 \mathrm{~h}$ e $30 \mathrm{~min}$ e com intervalo de $1 \mathrm{~h}$ entre elas, fazendo com que o experimento avançasse durante a tarde; assim, com a falta de luminosidade nas horas mais próximas da noite o experimento teve que ser interrompido e reiniciado na manhã seguinte; 
durante este intervalo, o solo foi mantido coberto com lona, para não sofrer influência do orvalho mas, na manhã seguinte, ocorreu aumento do bulbo sem ter havido acréscimo de água; nos outros tratamentos não houve tal problema.

A outra explicação para o aumento da maior área úmida em um sistema de menor vazão é que, no ato das medições, duas direções foram adotadas e sempre feitas as leituras e, devido à formação desigual do bulbo molhado na superfície (Figura 3) e/ou pelo fato do solo não ter sofrido grandes alterações, pode ter ocorrido a extrapolação desses dados.

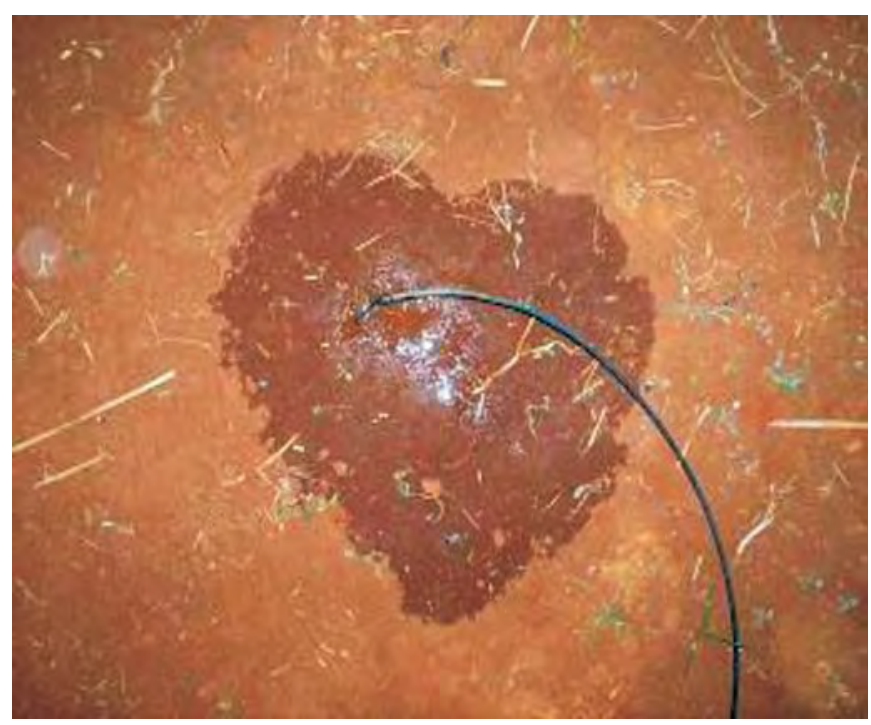

$\overline{\text { Figura 3. Formação desigual da superfície molhada e sentido das leituras }}$ do bulbo

Denomina-se disco saturado ou poça saturada, a região central do bulbo (próximo ao ponto de emissão) que tende à saturação superficial do solo durante a aplicação de água; então, quando se dava a formação de pequena lâmina de água na superfície, esta era considerada poça saturada e daí medida (Figura 2B); ao contrário do verificado na superfície úmida, deu-se uma estabilização na formação do disco saturado para os sistemas SUP4 e ENT4. Embora tenha ocorrido afloração da umidade no ENT2, não houve formação da poça saturada na superfície, impossibilitando sua leitura porém ocorrendo o mesmo em uma das três repetições do ENT4. As diferenças entre as áreas das poças saturadas foram de $0,0304 \mathrm{~m}^{2}$ para SUP4 e ENT4 e 0,0078 $\mathrm{m}^{2}$ entre os sistemas superficiais SUP2 e SUP4; não se encontrou relação entre a área molhada e o disco saturado, para o solo em estudo.

Os diâmetros máximos obtidos pelos sistemas foram de 0,6 m para o SUP2, 0,47 m para o sistema enterrado ENT2, 0,58 e 0,49 m para SUP4 e ENT4. Alves Júnior et al. (2004) encontraram, para o mesmo tipo de solo, diâmetro máximo molhado de $0,468 \mathrm{~m}$, aplicando $4 \mathrm{~L}$ de água $\left(\mathrm{Q}=2 \mathrm{~L} \mathrm{~h}^{-1}\right)$ e $0,548 \mathrm{~m}$, e $8 \mathrm{~L}$ de água $\left(\mathrm{Q}=4 \mathrm{~L} \mathrm{~h}^{-1}\right)$, semelhante aos valores encontrados neste trabalho para as mesmas relações de volume aplicado por vazão, no volume de $4 \mathrm{~L}$ aplicado com vazão $2 \mathrm{~L} \mathrm{~h}^{-1}$, o diâmetro máximo foi de $0,498 \mathrm{~m}$ e, no volume aplicado de $8 \mathrm{~L}$ com vazão de $4 \mathrm{~L} \mathrm{~h}^{-1}$, o diâmetro foi de 0,548 , para os sistemas superficiais; no entanto, a forma de aplicação de água do trabalho citado acima, foi contínua, sem intervalos; pode-se concluir, então, que a forma de aplicação, se contínua ou em intervalos, provoca pouca variação no diâmetro máximo superficial do bulbo.

Nas Figuras 4 a 7 se compararam os perfis de umidade $\left(\mathrm{m}^{3} \mathrm{~m}^{-3}\right)$ após cada aplicação de água no solo. Em virtude do grande número de gráficos, os bulbos escolhidos para representar os perfis foram os de 1, 2, 3, 7 e $10 \mathrm{~L}$; para melhor visualização, cada isolinha representa um acréscimo de $0,005 \mathrm{~m}^{3} \mathrm{~m}^{-3}$.

Avaliando-se primeiro a frente de umedecimento, constatou-se que nos sistemas superficiais esta frente ocorre prin-

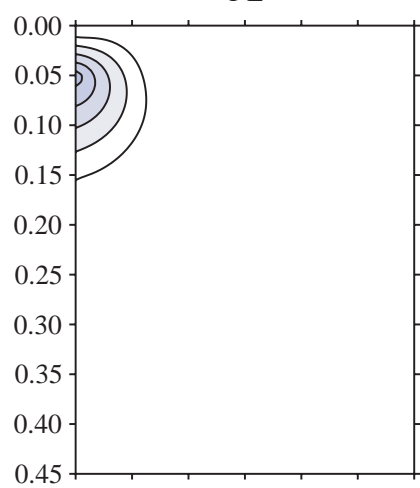

$3 \mathrm{~L}$

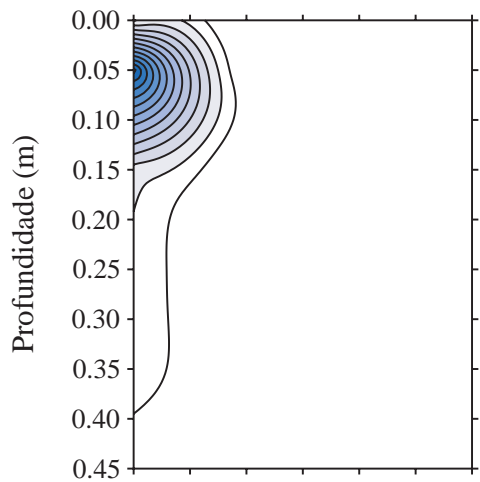

$10 \mathrm{~L}$

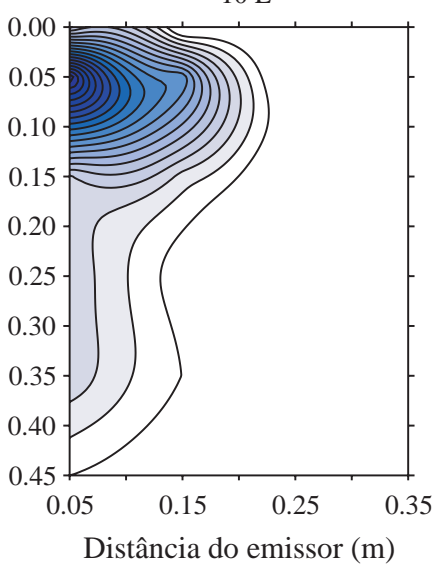

ENT 2

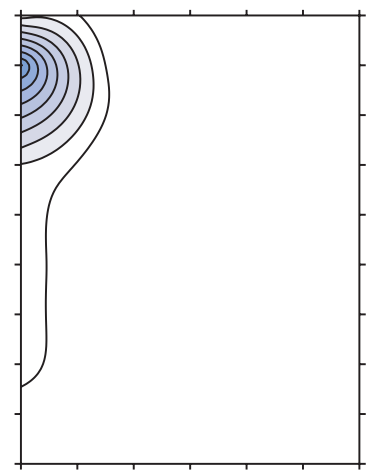

$7 \mathrm{~L}$

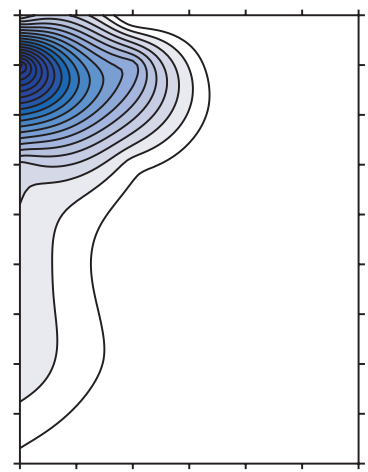

Legenda
Figura 4. Comparação entre os perfis de umidade $\left(\mathrm{m}^{3} \mathrm{~m}^{-3}\right)$ ao final do processo de aplicação da água no solo (1 L). Vazão de $2 \mathrm{~L} \mathrm{~h}^{-1}$ no sistema enterrado 
$1 \mathrm{~L}$

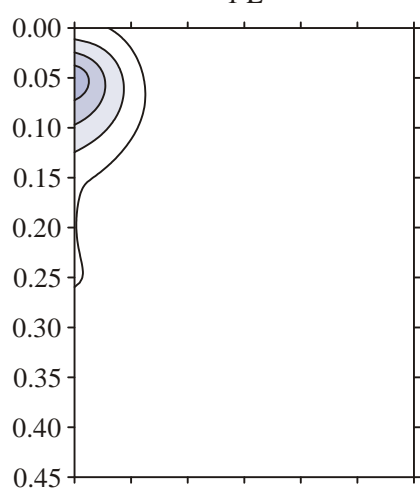

$3 \mathrm{~L}$

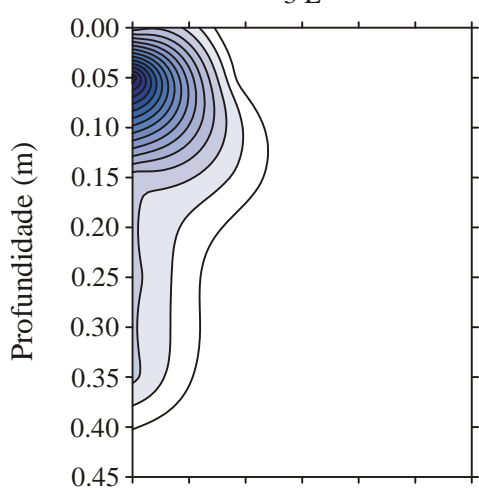

$10 \mathrm{~L}$

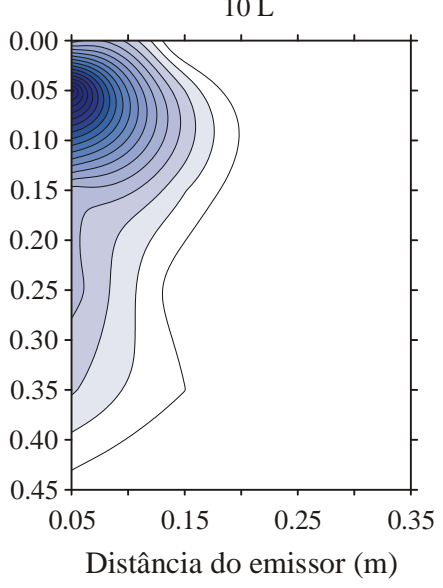

Figura 5. Comparação entre os perfis de umidade $\left(\mathrm{m}^{3} \mathrm{~m}^{-3}\right)$ ao final do processo de aplicação da água no solo (1 L). Vazão de $4 \mathrm{~L} \mathrm{~h}^{-1}$ no sistema enterrado

cipalmente nos três primeiros litros, com pouco aumento na forma; nos sistemas enterrados, nos três primeiros litros o maior aumento foi no sentido vertical passando para o horizontal e retornando o crescimento para o vertical, fazendo com que as frentes de molhamento ultrapassassem as sondas mais profundas $(0,45 \mathrm{~m})$. Silva et al. (2003) aplicando $8,38 \mathrm{~L}$ na superfície, atingiram a profundidade máxima de $0,40 \mathrm{~m}$ para a vazão de $2 \mathrm{~L} \mathrm{~h}^{-1}$, aproximadamente o dobro da atingida pelo SUP2.

Ao dobrar a vazão, se deu uma das maiores dimensões do bulbo molhado, tanto vertical como horizontal, observação esta confirmada por Mendonça Jr. et al. (2003) e Souza \& Matsura (2004); no entanto, os últimos autores discordam
SUP 2
$1 \mathrm{~L}$

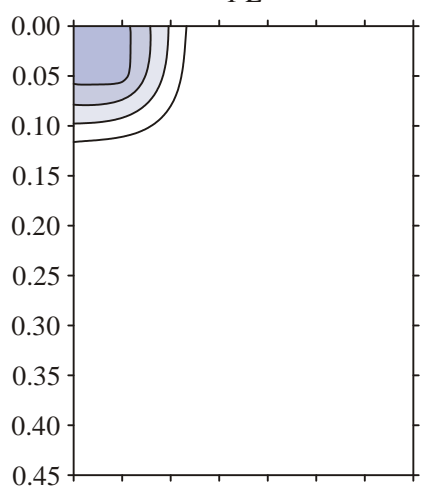

$3 \mathrm{~L}$
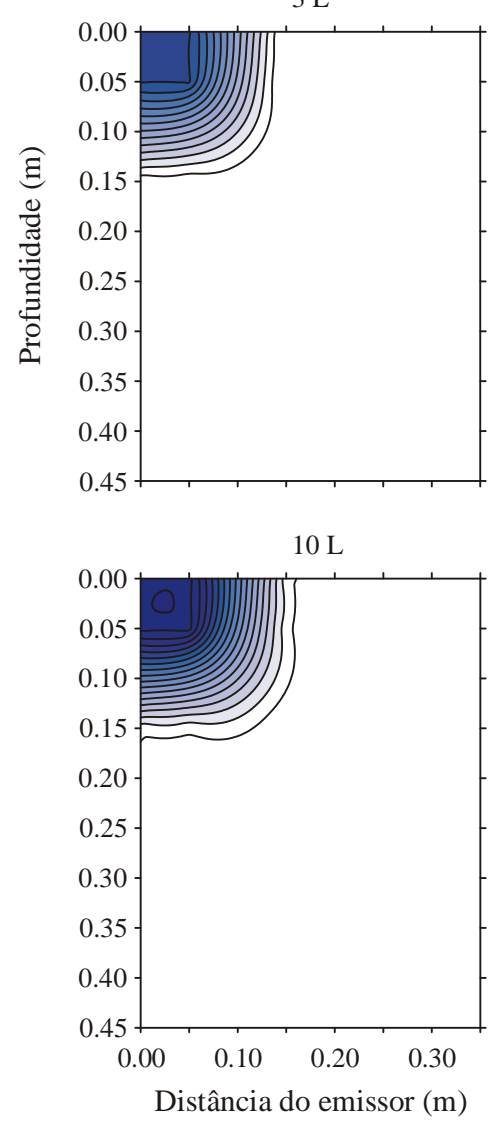

$2 \mathrm{~L}$

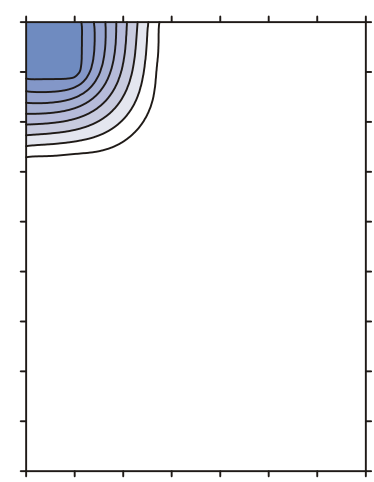

$7 \mathrm{~L}$

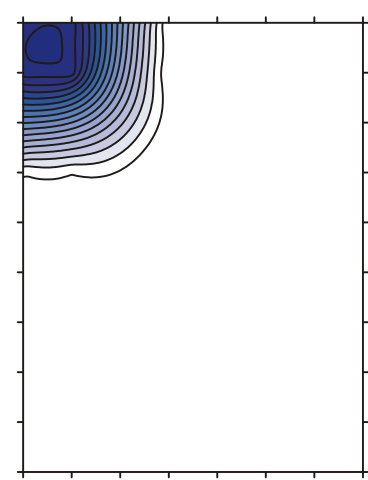

Legenda

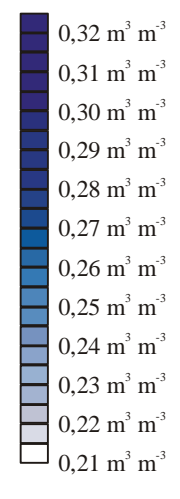

Figura 6. Comparação entre os perfis de umidade $\left(\mathrm{m}^{3} \mathrm{~m}^{-3}\right)$ ao final do processo de aplicação da água no solo (1 L). Vazão de $2 \mathrm{~L} \mathrm{~h}^{-1}$ no sistema superficial

quanto ao movimento vertical, dizendo que tende a diminuir. O aumento vertical nos sistemas enterrados é superior ao superficial em aproximadamente $0,30 \mathrm{~m}$, discordando de Coelho et al. (2005b) que encontraram menores valores de expansão lateral para emissores enterrados.

Apesar da menor área superficial molhada, os sistemas enterrados disponibilizaram água para este solo, a uma distância maior do emissor. Segundo Silva et al. (2003) dentre outros fatores a umidade do solo pode interferir na formação do bulbo, sobretudo nos sistemas enterrados, já que havia alta umidade $\left(0,30 \mathrm{~m}^{3} \mathrm{~m}^{-3}\right)$ encontrada abaixo de $0,15 \mathrm{~m}$ de profundidade, zona próxima à aplicação das vazões $(0,10 \mathrm{~m})$; além disso, os sistemas enterrados propor- 


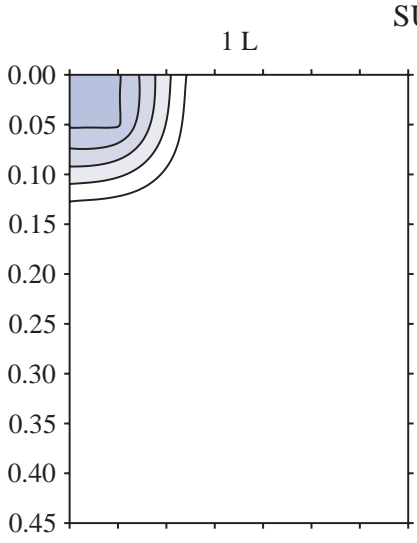

$3 \mathrm{~L}$
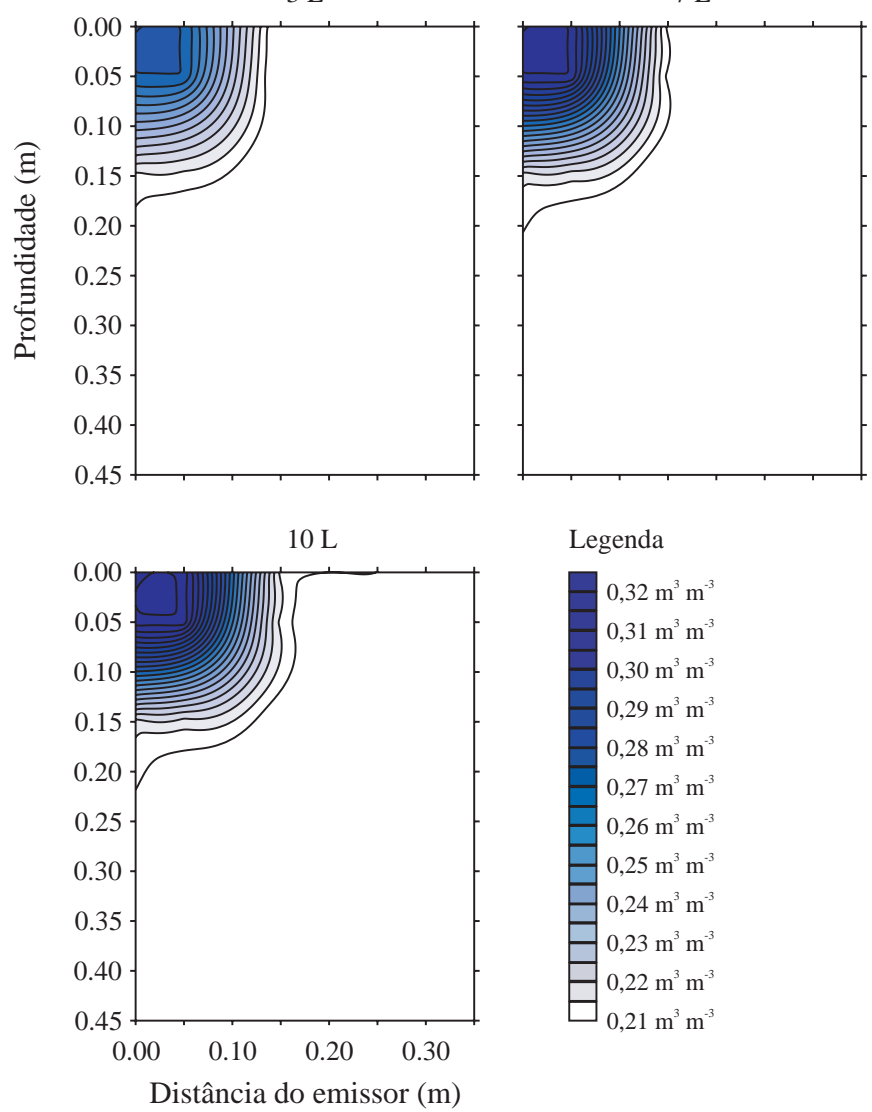

Legenda

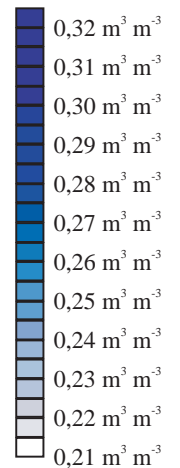

Figura 7. Comparação entre os perfis de umidade $\left(\mathrm{m}^{3} \mathrm{~m}^{-3}\right)$ ao final do processo de aplicação da água no solo (1 L). Vazão de $4 \mathrm{~L} \mathrm{~h}^{-1}$ no sistema superficial

cionaram ascensão da água à zona de germinação das sementes, fator que deve ser considerado na escolha da profundidade de instalação das linhas; outro fator importante seria a possível perda de água ocasionada pelo sistema enterrado, caso fosse inserida uma cultura de sistema radicular pouco profundo adaptando-se, neste caso, o sistema convencional.

Ressalta-se que as maiores diferenças de umidade (umidade após $10 \mathrm{~L}$ - umidade inicial) foram de $0,29 \mathrm{~m}^{3} \mathrm{~m}^{-3}-\mathrm{SUP} 2$; $0,32 \mathrm{~m}^{3} \mathrm{~m}^{-3}$ - SUP4; $0,31 \mathrm{~m}^{3} \mathrm{~m}^{-3}$ - ENT2 e $0,30 \mathrm{~m}^{3} \mathrm{~m}^{-3}-$ ENT4, variando pouco entre os sistemas; e esses aumentos de umidade por área foram maiores em locais próximos à sonda instalada a 0,05 x 0,05 m, próximas ao ponto de emissão, mesmo para o sistema enterrado onde ficava esta sonda 0,05 m acima do ponto de emissão. Monteiro (2007) trabalhando com gotejamento enterrado nas profundidades de 0,2 e $0,4 \mathrm{~m}$, encontrou valores maiores de umidade na profundidade de $0,5 \mathrm{~m}$ durante o ciclo da cultura do melão.

A partir do perfil dos gráficos das Figuras 4 a 7, realizaram-se as medidas das áreas dos perfis do bulbo (Figura 8). O aumento da área no perfil nos sistemas enterrados foi bem superior aos dos sistemas convencionais, enquanto no ENT4 o aumento da área após a décima leitura, foi 4,6 vezes maior que a primeira leitura; esta diferença foi de 3,8 vezes no ENT2, enquanto nos sistemas superficiais o aumento foi de apenas 2 vezes; pode-se inferir, daí, que existe uma concentração maior de água nos sistemas superficiais.

Comparativamente, a área do bulbo formada pelo sistema ENT4 foi 8,2\% maior que o ENT2, 67,3\% superior ao SUP4 e 71,0\% maior que o SUP2; Ben-Asher \& Phene (1993) encontraram que o volume do bulbo enterrado foi $46 \%$ maior que o superficial para um solo de textura franco-argilosa.

A estabilização do crescimento do bulbo formado no perfil do solo ocorreu após 3 L (3 h) nos sistemas superficiais, contrariando os dados de Nogueira (1998) que, trabalhando em solo franco argiloso, confirmou estabilização após 24 h.

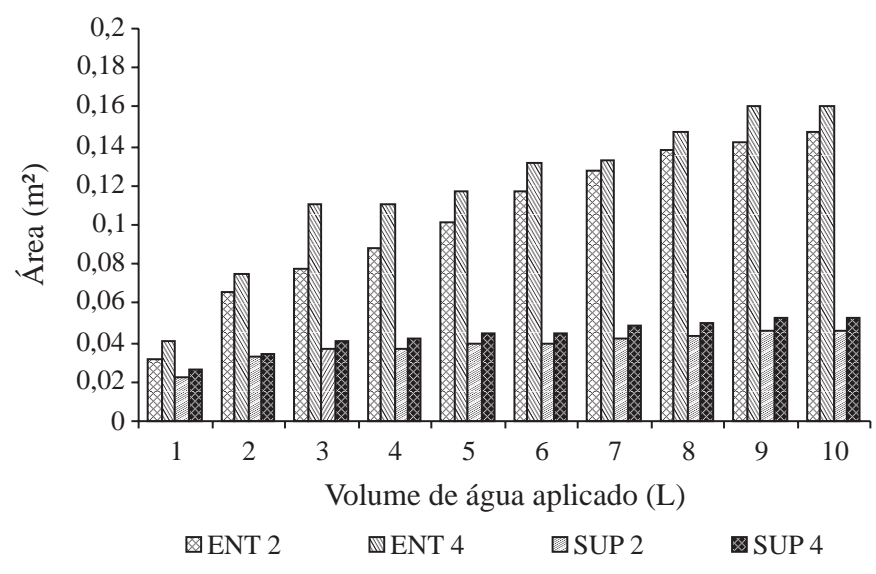

Figura 8. Comparação entre os perfis de umidade $\left(\mathrm{m}^{3} \mathrm{~m}^{-3}\right)$ ao final do processo de infiltração de aplicação da água no solo $(1 \mathrm{~L})$. Vazão de $2 \mathrm{~L} \mathrm{~h}^{-1}$ no sistema superficial

Na Figura 9 se encontram os valores dos Coeficientes de Uniformidade de Christiansen (CUC) para a umidade, calculados a partir da região de controle para as diferentes vazões e profundidades de aplicação. Os dados foram divididos em dois gráficos, para facilitar a visualização.

Nota-se, inicialmente, que os sistemas superficiais apresentaram melhores valores de uniformidade 28,22 e $20,31 \%$ (SUP2 e SUP4); esta situação foi mantida até a aplicação de $4 \mathrm{~L}$ para os sistemas de vazão $4 \mathrm{~L} \mathrm{~h}^{-1}$, e até os $7 \mathrm{~L}$, para os de vazão $2 \mathrm{~L} \mathrm{~h}^{-1}$; a partir desses pontos, os sistemas enterrados indicaram recuperação da uniformidade através do aumento do volume de água aplicado; em contrapartida, os sistemas superficiais iniciaram um decréscimo acentuado da uniformidade, ficando abaixo de 5\% após o nono litro aplicado. Analisando-se o gráfico em que os sistemas de vazão 


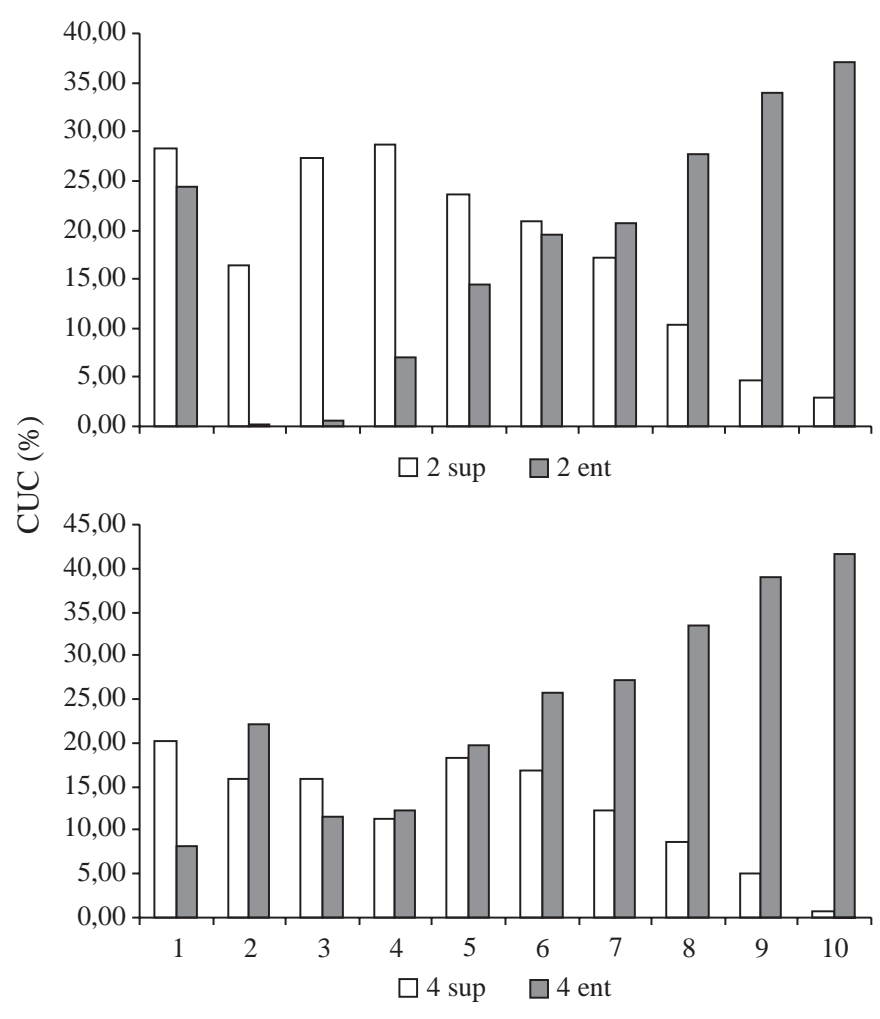

Figura 9. Coeficiente de Uniformidade de Christiansen para a umidade em função da vazão e do sistema para uma região de controle

$2 \mathrm{~L} \mathrm{~h}^{-1}$ e caso se utilizassem linhas ao invés de colunas, seria possível verificar a formação de um $\mathrm{X}$ formado pelo encontro das linhas do $\mathrm{CUC}_{\mathrm{SUP} 2}$ e CUC $\mathrm{ENT2}_{\text {. }}$.

Os melhores valores de uniformidade foram, até os $4 \mathrm{~L}$, quase que totais do SUP2; após isto, o ENT4 apresentou todos os melhores valores nos últimos $6 \mathrm{~L}$, cujos comentários, de forma negativa, também se encaixam nos sistemas ENT2 e SUP4, em que no sistema de vazão 2 se encontraram os 4 piores valores, até a vazão de $5 \mathrm{~L}$, e nos litros finais os piores valores couberam ao SUP4.

Não foi possível descrever a profundidade ideal $(0,0$ ou $0,10 \mathrm{~m}$ ) e muito menos a vazão ( 2 ou $4 \mathrm{~L} \mathrm{~h}^{-1}$ ) para ser indicada como padrão; e menos ainda, descrever o tratamento que apresentou melhores resultados, cuja definição vai depender de vários fatores, como profundidade efetiva do sistema radicular da cultura a ser irrigada, tipo, volume de água aplicado etc.

\section{CONCLUSÕES}

1. Em relação aos sistemas superficiais, os sistemas enterrados apresentaram menor área superficial molhada, atingiram maior largura e profundidade e disponibilizaram água a uma distância maior do ponto de emissão.

2. Os sistemas enterrados tenderam a melhorar a uniformidade de umidade com o aumento do volume de água aplicado enquanto os sistemas superficiais apresentaram efeito inverso.

3. As maiores concentrações de água foram obtidas próximas ao ponto de emissão.
4. Não foi possível determinar a profundidade ideal nem a vazão mais adequada.

\section{LITERATURA CITADA}

Alves Júnior, J.; Lourenção, M. S.; Silva, T. J. A., Silva, C. R.; Folegatti, M. V. Distribuição do sistema radicular de plantas jovens de lima ácida 'Tahiti' sob diferentes níveis de irrigação. Irriga, v.9, n.3, p.270-281, 2004.

Ben-Asher, J.; Phene, C. J. Analysis of surface and subsurface drip irrigation using a numerical model. In: Jorgensen, G. S.; Norum, K. N. Subsurface drip irrigation. Theory, practices and application. Fresno: California Center of Irrigation Technology. 1993. p.185-201.

Christiansen, J. E. The uniformity of application of water by sprinkler systems. Agricultural Engineering, v.22, p.89-92, 1941.

Clothier, B. E.; Sauer, T. J. Nitrogen transport during drip fertigation with urea. Soil Science Society of America Journal, v.52, p.345-349, 1988.

Coelho, E. F.; Or, D; Sousa, V. F. Avaliação de parâmetros hidráulicos para modelos de distribuição de água no solo sob gotejamento. Pesquisa Agropecuária Brasileira, v.34, n.4, p.651-657, 1999.

Coelho, E. F.; Santos, M. R.; Coelho Filho, M. A. Distribuição de raízes de mamoeiro sob diferentes sistemas de irrigação localizada em Latossolo de tabuleiros costeiros. Revista Brasileira de Fruticultura, v.27, n.1, p.175-178, 2005a.

Coelho, E. F.; Vellame, L. M.; Coelho Filho, M. A. de. TDR para estimativa da umidade e condutividade elétrica do solo, com uso de multiplexadores. Revista Brasileira de Engenharia Agrícola e Ambiental, v.9, n.4, p.475-480, 2005b.

Coelho, R. D.; Faria, L. F.; Melo, R. F. Variação de vazão em gotejadores convencionais enterrados por intrusão radicular na irrigação de citrus. Irriga, v.11, n.2, p.230-245, 2006.

EMBRAPA - Empresa Brasileira de Pesquisa Agropecuária. Centro Nacional de Pesquisas de Solos. Sistema brasileiro de classificação de solos. Rio de Janeiro: Embrapa Solos, 1999. 212p.

Faria, L. F., Coelho, R. D., Resende, R. S. Variação de vazão de gotejadores de fluxo normal enterrados na irrigação do café. Engenharia Agrícola, v.24, n.3, p.589-602, 2004

Gomes, E. P.; Sousa, A. P. Produtividade da alface (Lactuca sativa L.) em função dos valores de lâminas de água aplicados por gotejamento superficial e subsuperficial. Irriga, v.7, n.1, p.35-41, 2002.

Marouelli, W. A.; Silva, W. L. C. Profundidade de instalação da linha de gotejadores em tomateiro para processamento industrial. Horticultura Brasileira, v.20, n.2, p.206-210, 2002.

Mendonça Júnior, C. F.; Levien, S. L. A.; Medeiros, J. F. de; Matos, J. de A.; Medeiros, P. R. F.; Barros, A. D. Dimensões de bulbo úmido em solos utilizados na irrigação por gotejamento superficial: Luvissolo. In: Congresso Brasileiro de Engenharia Agrícola, 32, 2003, Goiânia. Anais... Goiânia: SBEA, 2003. p.1-4.

Monteiro, R. O. C. Influência do gotejamento subterrâneo e do “mulching” plástico na cultura do melão em ambiente protegido. ESALQ/USP. Piracicaba, 2007. 178p. Tese Doutorado

Nogueira, C. C. P.; Coelho, E. F.; Leão, M. C. S. Características e dimensões do volume de um solo molhado sob gotejamento superficial e subsuperficial. Revista Brasileira de Engenharia Agrícola Ambiental, v.4, n.3, p.315-320, 2000. 
Oron, G.; Demalach, Y.; Gillerman, L.; David, I. Pear response to saline water application under subsurface drip irrigation. In: International Microirrigation Congress, 5, 1991. St. Joseph. Proceedings... St. Joseph: ASAE, 1991. p.97-103.

Ould Mohamed El-Hafedh, A. V.; Daghari, H.; Maalej, M. Analysis of several discharge ratespacing-duration combinations in drip irrigation system. Agricultural Water Management, v.52, p.33-52, 2001.

Silva, C. A.; Matos, J. de A.; Medeiros, J. F. de; Levien, S. L. A.; Dimensões de bulbo úmido em solos utilizados na irrigação por gotejamento superficial: Argissolo. In: Congresso Brasileiro de Engenharia Agrícola, 32, 2003, Goiânia. Anais... Goiânia: SBEA, 2003. p.1-4.

Souza, C. F.; Folegatti, M. V.; Silva, E. F. F.; Silva, C. R. Distribuição e armazenamento da solução no solo para o manejo da fertirrigação por gotejamento. In: Congresso Brasileiro de Engenharia Agrícola, 36, 2007. Bonito. Anais... Bonito: SBEA, 2007. CD-Rom
Souza, C. F.; Matsura, E. E. Distribuição da água no solo para o dimensionamento da irrigação por gotejamento. Revista Brasileira de Engenharia Agrícola e Ambiental, v.8, n.1, p.7-15, 2004.

Souza, C. F.; Matsura, E. E.; Folegatti, M. V.; Coelho, E. F.; Or, D. Sondas de tdr para a estimativa da umidade e da condutividade elétrica do solo. Irriga, v.11, n.1, p.12-25, 2006.

Souza, E. A.; Coelho, E. F.; Paz, V. P. S. Distribuição da umidade num perfil do solo irrigado por gotejamento superficial e subsuperficial. Ciência e Agrotecnologia, v.31, n.4, p.1161-1166, 2007.

Tommaselli, J. T. G.; Bacchi, O. O. S. Calibração de um equipamento de TDR para medida de umidade de solos. Pesquisa Agropecuária Brasileira, v.36, n.9, p.1145-1154, 2001.

Wu, I. P.; Gitlin, H. M. Drip irrigation application efficiency and schedules. Transactions of the ASAE, v.26, p.92-99, 1983. 